\title{
Sex ratios of affected and transmitting members of multiple case families with neural tube defects
}

\author{
E C M Mariman, B C J Hamel
}

\begin{abstract}
In order to study the genetic aspects of the relation between neural tube defects and sex, we selected families with at least two closely related affected members. The sex ratios of both affected and normal transmitting persons were determined in these multiple case families. Our results indicate that there is a relation between the position of the lesion in the spine and sex. Furthermore, the affected persons in one family show significant concordance for sex as shown by the analysis of families with just two affected members. To our surprise, the group of normal transmitters appears to consist of significantly more females than males. This is in contrast to similar families with non-syndromic cleft lip \pm palate, where males predominate both among affected persons and normal transmitters. Finally, affected females most often inherited the predisposition to a neural tube defect from their mother. The possible role of inherited factors is discussed.

( $\mathcal{H}$ Med Genet 1992;29:695-8)
\end{abstract}

Many multifactorial disorders are known to occur with a different incidence in males and females, including neural tube defects (NTD), which seem to occur more often in females than in males. ${ }^{1}$ A detailed study has shown a correlation between the position of the lesion along the spine and sex. ${ }^{2}$ Lesions above the thoracolumbar boundary are seen more frequently in females, while lower lesions are associated with the male sex. In searching for an explanation, it has been postulated that these 'upper' and 'lower' lesions might reflect the disturbance of different developmental processes, that is, neurulation in females and canalisation in males. ${ }^{34}$ However, more recent data strongly indicate a common aetiology for all lesions irrespective of their location..$^{5-8}$ As yet, the precise nature of the relation between NTD and sex remains unclear. The present study was undertaken to clarify the sex specific aspects of NTD. Since genetic determination can be regarded as a common denominator, we have focused our attention on a selected group of multiple case families with NTD.

\section{Methods}

Multiple case families with NTD were selected in collaboration with the Dutch patient organisation BOSK and from the records of our institute. The criteria for includ- ing a family in our study were that (1) there should be at least two affected members and (2) the relationship between them was not more distant than third degree. Furthermore, cases of NTD as part of a syndrome, such as trisomy 18 or Meckel syndrome, were disregarded. In total, 112 families were identified and data were collected on the type of defect and the sex of each patient. Pedigree analysis allowed the identification of unaffected persons who had transmitted the trait, that is, predisposition to NTD development, on to the next generation. The sex of each of these 'normal transmitters' was scored. An example of how the different criteria were used is shown in the figure. In order to detect possible effects of ascertainment, multiple case families with non-syndromic cleft lip \pm palate were selected from the records of our institute using the same criteria as were used for the selection of NTD families. Since both cleft lip \pm palate and NTD are multifactorial congenital malformations, and since for both disorders the families were selected in the same way and from the same source, it is likely that effects of ascertainment will influence the results obtained with either set of families similarly.

The statistical evaluation of our data was done by the sign test. Within each defined category (patients, normal transmitters, affected pairs) the statistical significance of the deviation from unity was determined either for the male/female ratio or for the equal/unequal sex ratio. No comparison was made between the different categories. The two tailed Fisher exact test was used to detect possible differences in the number of sex concordant affected family members with either a first or a second/third degree relationship.

\section{Results}

TYPES OF NEURAL TUBE DEFECT AND CORRESPONDING MALE/FEMALE RATIOS

In the selected multiple case families a total of 265 affected persons was counted and for 241 of them the type of defect was recorded (table 1). Spina bifida in a variety of clinical manifestations constitutes the largest number of cases followed by anencephaly and, finally, a collection of rarer types of NTD such as craniorachischisis and iniencephaly. When the male/ female ratio was determined, the spina bifida category gave a ratio of $1 \cdot 2$, while for the other cases with known type of affection altogether a ratio of 0.7 was calculated (table 1 ). The latter group, which shows an association with female sex, contains exclusively defects with lesions in the 'upper' region. However, despite the fact that we were not able to sort out most of the

\footnotetext{
Received 4 December 1991 Revised version accepted 16 March 1992.

Human Genetics,

9101, $6500 \mathrm{HB}$

Netherlands.

B C J Hamel

Correspondence to
} 
Table 1 Incidence of different types of neural tube defect occurring in multiple case families.

\begin{tabular}{lrrrrr}
\hline Type of NTD & Total & Male & Female & NR $^{*}$ & M/F \\
\hline Spina bifida & 184 & 90 & 75 & 19 & $1 \cdot 2$ \\
Anencephaly & 38 & 11 & 14 & 13 & \\
SB + anencephaly & 9 & 5 & 3 & 1 & \\
Craniorachischisis & 3 & 0 & 2 & 1 \\
Encephalocele & 6 & 0 & 5 & 1 & $0 \cdot 7$ \\
Iniencephaly & 1 & 1 & 0 & 0 & \\
Unknown & 24 & 6 & 3 & 15 & \\
\hline
\end{tabular}

*NR= sex not recorded.

individual cases, the group of patients with spina bifida is heterogeneous with respect to the location of the lesion and includes defects in both the 'upper' and 'lower' regions. At the same time the sex ratio shifts towards the male sex. These findings suggest that for familial cases of NTD there is a relation between lesion/position and sex, which is identical to that which has been observed for randomly selected NTD patients. ${ }^{2}$ It should be noted that the sex of quite a number of patients is not known. This is especially the case for the second category where 16 out of 57 patients are of unidentified sex (table 1). Although it cannot be excluded, there is no reason to suspect that the male/female ratio among these unknown cases would differ from that of patients with known sex in the same category.

\section{CONCORDANCE FOR SEX AMONG PATIENTS OF TWO CASE FAMILIES}

When families with two affected sibs were examined, in 18 of 29 families the affected sibs were of the same sex, suggesting that in nuclear families there is a tendency towards concordance for sex among affected sibs. This

Table 2 Analysis of families with two affected members with 'upper' type of lesions for concordance of sex.

\begin{tabular}{|c|c|c|c|}
\hline Affected proband & Affected relative & $\begin{array}{l}\text { Degree of } \\
\text { relationship }\end{array}$ & Sex \\
\hline $\begin{array}{l}\text { Craniorachischisis } \\
\text { Anencephaly } \\
\text { Anencephaly } \\
\text { Anencephaly } \\
\text { Anencephaly + SB } \\
\text { Anencephaly + SB } \\
\text { Anencephaly }\end{array}$ & $\begin{array}{l}\text { Craniorachischisis } \\
\text { Spina bifida, thoracic } \\
\text { Anencephaly } \\
\text { Encephalocele } \\
\text { Anencephaly + SB } \\
\text { Anencephaly } \\
\text { Iniencephaly }\end{array}$ & $\begin{array}{l}1 \\
1 \\
3 \\
2 \\
1 \\
1 \\
1\end{array}$ & $\begin{array}{l}\text { Same (female) } \\
\text { Same (female) } \\
\text { Same (male) } \\
\text { Same (female) } \\
\text { Same (female) } \\
\text { Different } \\
\text { Different }\end{array}$ \\
\hline
\end{tabular}

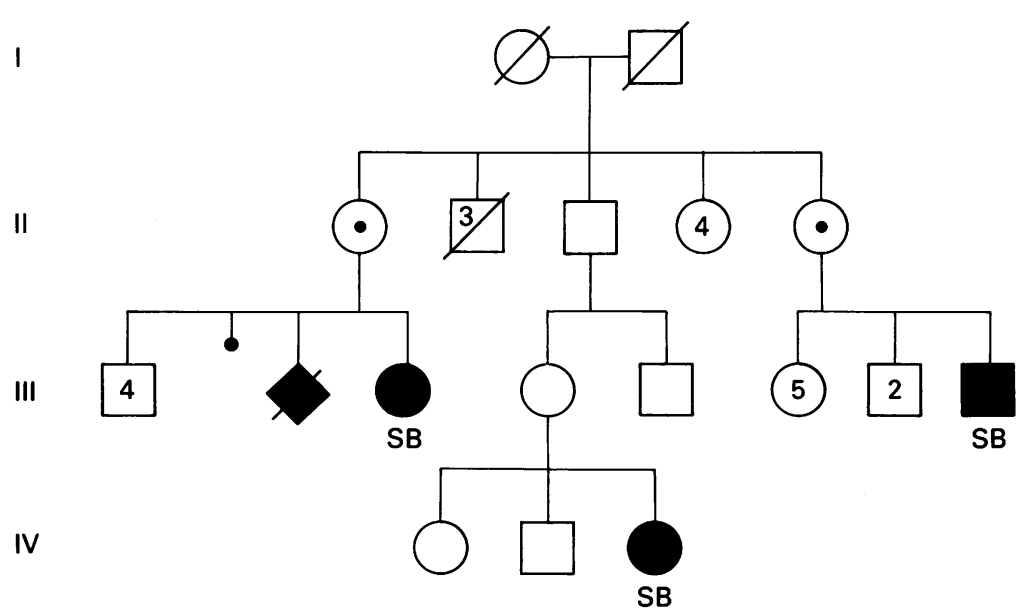

An example of a multiple case family with NTD. According to the criteria described in the Methods section only the two closely related persons with spina bifida (III.6 and III.16) and the two connecting normal transmitters (II.1 and II.10) have been included in our study. Patient IV.3 has a fourth degree relationship with the other affected members and has therefore been excluded from our study. SB=spina bifida. tendency apparently is not restricted to nuclear families, because families where the affected members are second or third degree relatives show the same phenomenon. Here, for 23 out of 35 families the affected members were found to be of similar sex. Overall, in 41 of 64 families the two affected members were of the same sex, with 21 male and 20 female cases. The observed concordance for sex shows statistical significance (sign test, $\mathrm{p}<0.02$ ) and seems to be independent of the degree of relationship between the two affected members (1st $v$ 2nd/3rd, Fisher $\mathrm{p}=0.80$ ).

It is tempting to speculate that the observed concordance for sex might occur in parallel with a concordance for the location of the lesion linked together by the association between location and sex. This hypothesis cannot be firmly tested with our present data, because for the majority of our families specific information on the lesion is lacking. Nevertheless, we have been able to select seven families in which the affected members are concordant for an 'upper' location of the lesion. As can be seen in table 2, in five of these families the affected members are of the same sex, which is in line with the proposed hypothesis. Obviously, more data have to be gathered before a more definite conclusion can be drawn.

\section{SEX RATIO OF NORMAL TRANSMITTERS AND} MODE OF TRANSMISSION

Besides affected persons, we also analysed the group of normal transmitters, that is, persons who have passed the predisposition for NTD on to the next generation (figure). In this group a deviation from unity was observed in the male/female ratio $(M / F=0 \cdot 7$, table 3$)$ with a significant shift towards the female sex (sign test, $\mathrm{p}<0.02$ ).

Since most of our families were selected from the records of our institute, the observed female preponderance might be the result of an effect of ascertainment, assuming that maternal relatives of an affected proband are more inclined to request genetic counselling than paternal relatives. This was investigated by performing a similar analysis of multiple case families with non-syndromic cleft lip \pm palate (see Methods). In these families, a male/female ratio of 1.6 was found for affected persons (table 3, p $<0.01$ ), which is almost identical to that reported for randomly selected cases with cleft lip \pm palate. ${ }^{9}$ For the group of normal transmitters a ratio of 1.8 was calculated (table $3, p<0.02$ ). The fact that the male/female ratio of normal transmitters of NTD and of cleft lip \pm palate shifts towards different sexes argues against a significant bias of ascertainment in our results.

The large number of women in the group of normal transmitters suggests that the affected persons in our families might have gained the predisposition to NTD from the mother. By examination of the pedigrees the parental origin of the predisposition to NTD was determined separately for affected males and females. The results show that more of the 
Table 3 Determination of the male/female ratio among affected persons and normal transmitters in multiple case families with either NTD or cleft lip \pm palate.

\begin{tabular}{llrrrrr}
\hline Type of defect & & Total & NR* & Male & Female & M/F \\
\hline Neural tube defects & Affected persons & 265 & 50 & 113 & 102 & $1 \cdot 1$ \\
Cleft lip \pm palate & Normal transmitters & 127 & 0 & 51 & 76 & 0.7 \\
& Affected persons & 97 & 4 & 58 & 37 & $1 \cdot 6$ \\
& Normal transmitters & 39 & 1 & 25 & 13 & $1 \cdot 8$ \\
\hline
\end{tabular}

* NR = sex not recorded.

affected females $(69 \%$, table 4$)$ have inherited the predisposition from their mother $(p<0.01)$. However, for affected males there is no tendency towards either of the parents.

\section{Discussion}

We have analysed multiple case families with NTD in order to obtain more insight into the relationship between NTD and sex. Our results indicate (1) an association between lesions above the thoracolumbar boundary and female sex, (2) concordance for sex between NTD patients in families with two affected members, and (3) a significant majority of females in the group of normal transmitters. Further, our data suggest that (4) affected women have more often inherited the predisposition to NTD from their mother.

According to Seller ${ }^{2}$ the relation between lesion/position and sex, as observed in randomly selected cases of NTD, might be correlated with sex specific spatiotemporal development of male and female embryos. Differences in the timing of early developmental processes have been observed in some strains of mice ${ }^{1011}$ where male and female embryos show a different number of somites at the time of neurulation. In this context it is tempting to ascribe the relation between NTD and sex to the disturbance of certain genetic factors ${ }^{12}$ that are implicated in early embryogenesis. The multiple case families that we have analysed provide an excellent basis for testing this possibility, because these families have been selected according to criteria which make a genetic contribution to the aetiology of the defects likely. Our findings indicate that the relation between lesion/position and sex, as was observed with randomly selected patients with $\mathrm{NTD},{ }^{2}$ is also true for familial cases. Furthermore, the fact that within these families the patients with NTD show concordance for sex seems to corroborate the involvement of inherited factors. It is important to identify such factors and study their function, because this would give direct information on the aetiology of NTD.

There are various mechanisms by which inherited factors might cause embryogenesis to

Table 4 Determination of the parental origin of the predisposition to NTD by analysis of pedigrees.

\begin{tabular}{llll}
\hline Origin of the trait & & No & $\%$ \\
\hline Affected male & Paternal & 21 & 47 \\
& Maternal & 24 & 53 \\
Affected female & Paternal & 16 & 31 \\
& Maternal & 36 & 69 \\
\hline
\end{tabular}

be different for females and males. Genes coding for sex specific products, like sex hormones and their receptors, might be involved. However, knowing that neurulation, at least in mice, precedes gonadal differentiation, ${ }^{12}$ this is probably of limited importance. More likely, mechanisms influencing the level of expression of certain genes might play a role. ${ }^{13}$ In this respect it is interesting to note that variability in gene dosage resulting from anomalous $\mathrm{X}$ inactivation has been proposed as an aetiological factor for NTD, ${ }^{14}$ which would of course imply that important genes are located on the $\mathrm{X}$ chromosome. In fact, genetic studies do indicate the existence of $\mathrm{X}$ linked genes involved in neural tube defects. ${ }^{15-19}$

Although a dosage effect of $\mathrm{X}$ linked genes may provide a basis for understanding some of our results, imprinting of maternally inherited developmental genes more easily explains the female preponderance in the group of normal transmitters. Recent studies on the genes for insulin-like growth factor 2 and its receptor have shown that imprinting can indeed influence prenatal development in the mouse. ${ }^{2021}$ Finally, still other mechanisms might be involved, such as the action of maternal effect genes ${ }^{22}$ or maternal influences on the development of the embryo. The latter possibility has recently gained weight from the study of Steegers-Teunissen $e t a^{23}$ who found a high percentage of heterozygosity for homocysteinaemia in mothers of children with NTD. Although the data in this study are preliminary, it is interesting that the women who were examined belong to almost the same regional population that we have selected our families from.

It is obvious that the findings reported here only mark the beginning of a more profound study into the relations between NTD and sex. We feel that firm conclusions on this matter, finally, may prove to be useful for genetic counselling of families with neural tube defects and hope that this report will initiate similar studies by others.

We thank the Dutch Patient Organisation BOSK for their assistance in the ascertainment of multiple case families. We also want to thank Dr J C M Hendriks, Department of Medical Statistics, University Hospital Nijmegen, for the analyses of our data. This study was performed with financial support from the 'Princes Beatrix Fonds' (grant no 90-3154).

1 Carter CO. Clues to the aetiology of neural tube malformations. Dev Med Child Neurol 1974;16(suppl 32):3-15. 2 Seller MJ. Neural tube defects and sex ratios. $\mathrm{Am} \mathrm{f}$ Med Genet 1987;26:699-707.

3 Toriello HV, Higgins JV. Possible causal heterogeneity in spina bifida cystica. Am $\mathcal{f}$ Med Genet 1985;21:13-20. 
4 Hall JG, Keena BA. Adjusting recurrence risks for neural tube defects based on B.C. data. Am 7 Hum Genet 1986;39(suppl):64A

5 Frecker MF, Fraser FC, Heneghan WD. Are "upper" and "lower" neural tube defects aetiologically different? $\mathcal{f}$ Med Genet 1988;25:503-4.

6 Seller MJ. Neural tube defects: are neurulation and canalization forms causally distinct? Am $f$ Med Genet 1990;35:394-6.

7 Drainer E, May HM, Tolmie JL. Do familial neural tube defects breed true? F Med Genet 1991;28:605-8.

8 Török O, Papp Z. Are the neurulation and canalization forms of neural tube defects causally distinct? $\mathrm{Am} \mathcal{J}$ Med Genet 1991;39:241.

9 Owens JR, Jones JW, Harris F. Epidemiology of facial clefting. Arch Dis Child 1985;60:521-4.

10 Tsunoda $Y$, Tokunaga $T$, Sugie $T$. Altered sex ratio of live young after transfer of fast- and slow-developing mouse embryos. Gamete Res 1985;12:301-4.

11 Seller MJ, Perkins-Cole KJ. Sex difference in mouse embryonic development at neurulation. $\mathcal{f}$ Reprod Fertil 1987;79:159-61.

12 Goldbard SB, Warner CM. Genes affecting the timing of early mouse embryo development. Biol Reprod early mouse

13 Mintz B, Russell ES. Gene-induced embryological modifications of primordial germ cells in the mouse. $\mathcal{F}$ Exp Zool 1957;134:207-37.

14 James WH. Anomalous X chromosome inactivation: the link between female zygotes, monozygotic twinning, and neural tube defects? $\mathcal{F}$ Med Genet 1988;25:213-6.
15 Toriello $\mathrm{H}$, Warren S, Lindstrom J. Possible X-linked anencephaly and spina bifida - report of a kindred. $A m \mathcal{F}$ Med Genet 1980;6:119-21.

16 Toriello $\mathrm{H}$. Report of a third kindred with $\mathrm{X}$-linked anencephaly/spina bifida. Am $\mathcal{F}$ Med Genet 1984;19:411-2.

17 Oman-Ganes L, Shokeir M. Neural tube defects: possible $\mathrm{X}$-linked recessive inheritance. Am $\mathcal{f}$ Hum Gene 1984;36:67(S).

18 Baraitser $M$, Burn J. Neural tube defects as an X-linked condition. Am f Med Genet 1984;17:383-5.

19 Jensson O, Arnason A, Gunnarsdottir H, Petursdottir I Fossdal R, Hreidarsson S. A family showing apparent X Fossdal $R$, Hreidarsson $S$. A family showing apparent $\mathbf{X}$ Med Genet 1988;25:227-9.

20 Barlow DP, Stöger R, Herrmann BG, Saito K, Schweifer $\mathrm{N}$. The mouse insulin-like growth factor type-2 receptor is imprinted and closely linked to the Tme locus. Nature 1991;349:84-7.

21 Ferguson-Smith AC, Cattanach BM, Barton SC, Beechy $\mathrm{CV}$, Surani MA. Embryological and molecular investigations of parental imprinting on mouse chromosome 7 . Nature 1991;351:667-9.

22 Wilson GN, Stout JP, Schneider NR, Zneimer SM, Gilstrap LC. Balanced translocations $12 / 13$ and situs abnormalities: homology of early pattern formation in man and lower organisms? Am $\mathcal{Y}$ Med Genet 1991;38:601-7.

23 Steegers-Teunissen RPM, Boers GHJ, Trijbels FJM, Eskes TKAB. Neural-tube defects and derangement of homocysteine metabolism. N Engl f Med 1991;324:199. 